\title{
The GABA transporter 1 (SLC6A1): a novel candidate gene for anxiety disorders
}

\author{
C. K. Thoeringer $\cdot$ S. Ripke $\cdot$ P. G. Unschuld $\cdot$ S. Lucae $\cdot$ \\ M. Ising $\cdot$ T. Bettecken $\cdot$ M. Uhr $\cdot$ M. E. Keck $\cdot$ B. Mueller-Myhsok $\cdot$ \\ F. Holsboer · E. B. Binder $\cdot$ A. Erhardt
}

Received: 14 March 2008/Accepted: 30 May 2008/Published online: 8 July 2008

(C) The Author(s) 2008

\begin{abstract}
Recent evidence suggests that the GABA transporter 1 (GAT-1; SLC6A1) plays a role in the pathophysiology and treatment of anxiety disorders. In order to understand the impact of genetic variation within SLC6A1 on pathological anxiety, we performed a case-control association study with anxiety disorder patients with and without syndromal panic attacks. Using the method of sequential addition of cases, we found that polymorphisms in the $5^{\prime}$ flanking region of SLC6A1 are highly associated with anxiety disorders when considering the severity of syndromal panic attacks as phenotype covariate. Analysing the effect size of the association, we observed a constant increase in the odds ratio for disease susceptibility with an increase in panic severity (OR $\sim 2.5$ in severely affected patients). Nominally significant association effects were observed considering the entire patient sample. These data indicate a high load of genetic variance within SLC6A1 on pathological anxiety and highlight GAT-1 as a promising target for treatment of anxiety disorders with panic symptoms.
\end{abstract}

C. K. Thoeringer and S. Ripke contributed equally to this work. Dedicated to the Special Issue "Fear, Anxiety and Anxiety Disorder".

Electronic supplementary material The online version of this article (doi:10.1007/s00702-008-0075-y) contains supplementary material, which is available to authorized users.

C. K. Thoeringer $(\bowtie) \cdot$ S. Ripke · P. G. Unschuld · S. Lucae ·

M. Ising - T. Bettecken - M. Uhr - M. E. Keck ·

B. Mueller-Myhsok · F. Holsboer · E. B. Binder · A. Erhardt

Max Planck Institute of Psychiatry,

Kraepelinstrasse 2-10, 80804 Munich, Germany

e-mail: thoeringer@mpipsykl.mpg.de

M. E. Keck

Neuroscience Center Zürich and Klinik Schlössli,

Zurich, Switzerland
Keywords GAT-1 - Single nucleotide polymorphisms · Anxiety disorders and panic - Sequential addition of cases . GABA system genetics

\section{Introduction}

Anxiety disorders are frequent psychiatric conditions in the general population with lifetime prevalence rates ranging from 13.6 up to $28.8 \%$ (Alonso et al. 2004; Kessler et al. 2005a). Due to high comorbidity rates with other psychiatric disorders and physical illness (e.g., Kessler et al. 2005b; Mayer et al. 2001; Merikangas et al. 2003) quality of life is seriously compromised and social disadvantage often arises resulting in impairment comparable to chronic somatic disorders.

A great number of studies have been carried out investigating the influence of genetic and environmental underpinnings of pathological anxiety. So far, epidemiological evidence suggests a familial aggregation of anxiety disorders (e.g., Horwath et al. 1995; Low et al. 2008; Nocon et al. 2007) which is highly attributable to genetic factors with heritability estimates around 30\% (e.g., Hettema et al. 2005). The understanding of the genetic mechanisms that contribute to development or maintenance of anxiety disorders may offer new insights in the pathophysiology of these disorders and potentially novel therapeutic strategies.

Several lines of preclinical and clinical evidence support the view that the $\gamma$-aminobutyric acid (GABA) system is a major candidate in the pathogenesis of anxiety, fear and related psychopathological conditions. It has been shown that pentylenetetrazole, an agent antagonizing $\mathrm{GABA}_{\mathrm{A}}$ receptor function, induces symptoms of anxiety, flash backs of traumatic memories and strong avoidance 
behaviour (Kalueff and Nutt 1996-1997). Conversely, augmentation of brain GABA function by positive allosteric modulators of $\mathrm{GABA}_{\mathrm{A}}$ receptors, e.g., using benzodiazepines, promotes rapid and profound anxiolysis in patients suffering from affective and anxiety disorders (Kalueff and Nutt 2007; Nemeroff 2003). Apart from pharmacological agents modulating the $\mathrm{GABA}_{\mathrm{A}}$ receptor, a novel class of drugs (initially developed as antiepileptic medication) targeting synaptic transport or metabolism of GABA has emerged in the clinical management of anxiety states (Rogawski and Loescher 2004; Zwanzger and Rupprecht 2005).

Among them, drugs have been developed that act by blockade of GABA transporters (GAT), thereby inhibiting GABA uptake from the synaptic cleft. Four subtypes of GATs, GAT-1, GAT-2, GAT-3 and Betaine/GABA transporter 1 (BGT-1) have been identified. GAT-1 constitutes the main neuronal transporter isoform that is abundantly expressed on presynaptic GABAergic terminals of neurons and on glial cells (Dalby 2003; Sarup et al. 2003). The first (and only) selective inhibitor of GAT-1 sites in clinical use is tiagabine. It has been approved for add-on therapy of partial-onset seizures in adults (LaRoche and Helmers 2004). In addition, several preliminary studies report that tiagabine is effective in psychiatric diseases such as panic disorder, generalized anxiety disorder, posttraumatic stress disorder, in which augmentation of brain GABA neurotransmission is thought to alleviate clinical symptoms (Carpenter et al. 2006; Connor et al. 2006; Pollack et al. 2005; Rosenthal 2003; Sheehan et al. 2007; Zwanzger et al. 2001).

In addition to the clinical benefits and relevance observed by psychotropic GAT-1 blockade in anxiety disorder patients, neurobiological evidence for aberrant GABAergic neuroinhibitory processes on the level of GABA release and reuptake comes from neuroimaging studies. Using magnetic resonance spectroscopy technique, lower levels of GABA in cortical areas and the basal ganglia of panic disorder patients (Goddard et al. 2001; Ham et al. 2007) and in the thalamus of patients suffering from social anxiety disorder (Pollack et al. 2008) as compared to healthy control subjects have been documented. In a preliminary follow-up analysis, Goddard et al. (2004a) report that the low cortical GABA levels in panic disorder patients is largely determined by familial and, possibly, genetic factors.

As a consequence, the SLC6A1 gene, which encodes the GAT-1 protein, can be considered an obvious candidate gene for human gene association studies investigating the genetic liability to anxiety disorders. In the present study, we performed a case-control association study investigating the genetic variance in SLC6A1 in anxiety disorder patients with syndromal panic attacks and matched control subjects. We focused on this phenotype due to the high frequency of panic attacks in anxiety disorder patients and good clinical response to drugs that enhance GABAergic neurotransmission.

\section{Methods}

Study population

The present study was approved by the local ethics committee. Written informed consent was obtained from all participating subjects.

The study included 238 adult patients consecutively recruited from the Anxiety Disorders Outpatient Clinic of the Max Planck Institute of Psychiatry in Munich presenting with the following anxiety disorders: panic disorder with agoraphobia (71.4\%), panic disorder without agoraphobia (13.0\%), agoraphobia (1.7\%), social phobia (7.6\%), specific phobia $(3.8 \%)$ and generalized anxiety disorder (2.5\%). Demographic and clinical data are shown in Table 1. Patients were diagnosed by trained psychiatrists using the structured clinical interview (SCID) for DSM-IV (Wittchen et al. 1997). All patients underwent a thorough medical examination including EEG, ECG and detailed hormone laboratory assessment. Anxiety disorders due to a medical or neurological condition or a comorbid Axis II disorder were exclusion criteria.

Table 1 Demographic and clinical characteristics of the study population

\begin{tabular}{lll}
\hline & Patients & Controls \\
\hline Total $N=505$ & & \\
$N$ & $238(47.1 \%)$ & $267(52.9)$ \\
Sex & & \\
Male (\%) & 37.8 & 39.2 \\
Female (\%) & 62.2 & 60.7 \\
Age (SD) (years) & $38.2(11.6)$ & $38.5(11.6)$ \\
Age of onset (SD) (years) & $27.4(11.2)$ & \\
PAS total (SD) & $29.8(9.8)$ & \\
Panic attacks (SD) & $6.5(3.1)$ & \\
Agoraphobia (SD) & $6.8(3.1)$ & \\
Anticipatory anxiety (SD) & $5.8(1.7)$ & \\
Disability (SD) & $6.1(2.8)$ & \\
Health concerns (SD) & $4.4(2.5)$ & \\
\hline
\end{tabular}

Quantitative analysis of severity of panic and anxiety symptoms using the panic and agoraphobia scale. Data are shown as the mean of the total panic and agoraphobia scale (PAS) score, the mean severity of panic attacks, phobic avoidance (agoraphobia), anticipatory anxiety, impairment of social relationships and work (disability) and assumption of somatic disease (health concerns). SD standard deviation 
Ethnicity was recorded using a self-reported questionnaire asking for nationality, language and ethnicity of the subject, his/her parents and grandparents. All included patients were Caucasians with $83 \%$ being of German and $17 \%$ of other European origin. Patients with Turkish, Oriental Asiatic and African origin were excluded from the analysis.

A total of 267 healthy control subjects matched for ethnicity (using the same questionnaire as for patients), gender and age were recruited at the Max Planck Institute of Psychiatry (Table 1). They were randomly selected from a Munich-based community sample and screened for the presence of mood disorder, anxiety disorders including OCD and PTSD, somatoform disorder, alcohol dependence, drug abuse, psychotic disorder, dissociative disorder NOS and eating disorder using a standardized diagnostic interview (DSM-IV M-CIDI) (Wittchen 1994; Wittchen and Pfister 1997). Only individuals with a negative lifetime history for these disorders were enrolled in the study.

Assessment of dimensional measures of panic and anxiety

We used the panic and agoraphobia scale (PAS) (Bandelow 1995) to assess the severity of the worst period of anxiety and panic symptoms and to further investigate associations with genetic polymorphisms in the GAT-1 gene. The total score on this scale revealed a moderate to high severity of panic and agoraphobia [mean score physician rating (SD): 29.8 (9.8)]. The sub-scores of PAS regarding the severity of panic attacks, phobic avoidance, anticipatory anxiety, impairment of social relationships and work as well as assumption of somatic disease are presented in Table 1. Ratings were performed by trained psychiatrists.

Psychopathological phenotyping of patients with the Hamilton Anxiety Scale revealed a mean score of 24.7 (SD 9.8), and the mean Hamilton Depression Scale score was 13.7 (SD 6.6) indicating moderate anxiety and low depression in these patients (Hamilton 1959, 1960).

DNA preparation, SNP selection and genotyping

On enrolment in the study, up to $40 \mathrm{ml}$ of EDTA blood was drawn from each subject and DNA was extracted using a standardized procedure (Puregene whole blood DNAextraction kit; Gentra Systems Inc., USA).

For the present study, SNPs were selected from the Illumina Sentrix Human-1 Genotyping 300K BeadChip system (Illumina Inc., San Diego, USA) and mapped to the coding region and in the flanking sequence $[n=20 ; 15 \mathrm{~kb}$ up- and downstream; from position 10997825 to 11055168 (hg18)] of the GAT-1 gene [SLC6A1 (NM_003042)] on chromosome 3p25.3 (Fig. 1). SNP genotyping of a total number of 20 SNPs (average inter-polymorphism distance $3.2 \mathrm{~kb}$ ) was performed at the Center for Applied GenoTyping, CAGT, at the Max Planck Institute of Psychiatry, Munich, Germany, using the Illumina InfiniumII technology and the protocols provided by the manufacturer. Genotype calling was according to the manufacturer's instructions. Cluster files for all SNPs were inspected by eye, and all intensities clustered well into the three canonical groups. The call rate for each SNP was $>99.6 \%$ (mean 99.9\%), and minor allele frequencies exceeded 6\%. The reproduction error rate was below $0.0003 \%$ as judged from repeated genotyping of five samples. Genotype datasets were checked for identical samples and relatedness (no identical samples were found). No SNP showed a significant deviation $(P<0.05)$ from Hardy-Weinberg equilibrium (Electronic supplementary material, Table 3 ).

Data analysis and statistics

All statistical analyses were performed using the WGPermer software, a tool for rapid analysis of large scale genome association studies (http://www.wg-permer.org). The association analysis for SNPs and phenotypes was conducted by $\chi^{2}$ tests applying an allelic model. This approach corresponds to the Armitage test of trend. As the individual tests are correlated, we used 100.000 permutations to adjust for multiple testing, namely the minimum $P$ method of Westfall and Young (1993).

Second, we carried out the Fisher product method for combining tests (Fisher 1932) to get overall significance levels for the whole set of polymorphisms within the candidate region. Again, the significance of combined tests was evaluated using permutation (Binder et al. 2004).

For the analysis of linkage disequilibrium (LD) and haplotype block delineation we used haplotypes estimated by HAPLOVIEW 4.0 (http://www.broad.mit.edu/mpg/ haploview). Blocks were defined using the confidence interval method described by Gabriel et al. (2002).

The level of significance for all statistical analyses was set to $5 \%$.

\section{Results}

A total number of 20 SNPs were genotyped within the SLC6A1 locus and flanking regions with all polymorphisms passing quality control (see "Methods"), and they were thus included in the statistical analysis.

To test for the effects of population stratification, we applied the method of genomic controls (Binder et al. 2004; Devlin and Roeder 1999) for the data obtained from the Illumina $300 \mathrm{~K}$ chip. Thereby, we calculated the allelic deviation between cases and controls using the $\chi^{2}$ statistics 
and compared the distribution of the obtained with the theoretically expected $\chi^{2}$ values. $\lambda$, the ratio of the median of the test statistics and the median of the theoretical distribution was 1.025 indicating almost no population stratification between our study samples.

\section{Case-control analysis}

In a first analysis of putative associations between anxiety disorders and genetic variability in SLC6A1, we tested for case-control differences in the distribution of alleles using a permutation-based correction (100.000 permutations) as implemented in the WG-Permer software (see Fig. 1). We found five polymorphisms of SLC6A1 to be nominally associated with the disease $(P<0.05$ : rs956053, rs2697153, rs2930152, rs1710879, rs2601126). Highest nominal case-control associations $(P<0.026)$ are listed in Table 2. Adjustment for multiple testing, however, revealed that none of them remained significantly associated (rs2930152: $P=0.202$; rs2697153: $P=0.238$; rs956053: $P=0.321)$. Fisher product combined gene-wide testing with 100.000 permutations yielded a $P$ value of 0.03151 . Despite only nominally association effects obtained for single SNPs, the results of a significant combined effect of all investigated polymorphisms as revealed by Fisher product testing strongly suggest a major role of SLC6A1 in the genetic susceptibility of pathological anxiety.

Analysis by sequential addition of cases

We then re-investigated these case-control associations using the method of sequential addition of cases (ordered
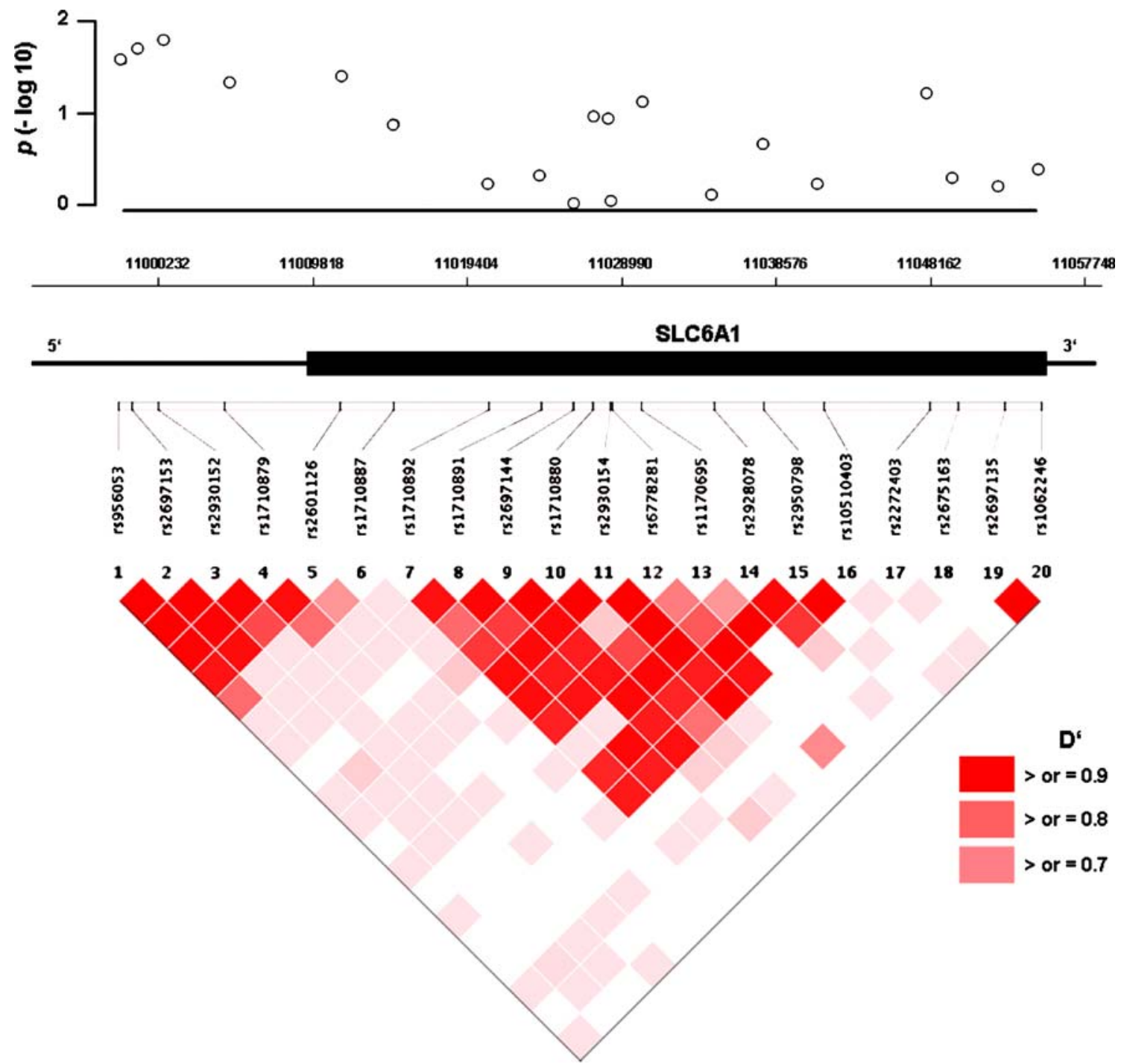

Fig. 1 Illustration and mapping of case-control $P$ values (nominal) for genotyped SNPs at the SLC6A1 locus (upper graph). Lower triangular graph illustrates linkage disequilibrium (LD) and block structure within the GAT-1 gene using $\mathrm{D}^{\prime}$ as a measure for LD 
Table 2 Association of GAT-1 single nucleotide polymorphisms with anxiety disorders

\begin{tabular}{lllr}
\hline SNPs & Patients & Controls & $P$ value \\
\hline rs2930152 & AA, 18.1; AG, 50.4; GG, 31.5 & AA, 13.9; AG, 43.8; GG, 48.7 & 0.0147 \\
rs2697153 & AA, 35.7; AG, 48.3; GG, 16.0 & AA, 46.8; AG, 40.4; GG, 12.8 & 0.0181 \\
rs956053 & CC, 54.6; CT, 41.2; TT, 4.2 & CC, 50.6; CT, 36.7; TT, 12.7 & 0.0263 \\
\hline
\end{tabular}

The three SNPs showing the lowest nominal $P$ values. Presentation of genotype distributions (\%) between anxiety disorder patients and controls; $\chi^{2}$ tests using the allelic model

Table 3 Classification of anxiety disorder patients according to the severity of syndromal panic attacks

\begin{tabular}{llc}
\hline Subsets & PA severity & Patients $(N)$ \\
\hline I & $0-12$ & 238 \\
II & $3-12$ & 198 \\
III & $6-12$ & 143 \\
IV & $7-12$ & 97 \\
V & $8-12$ & 60 \\
VI & $9-12$ & 33 \\
\hline
\end{tabular}

A severity index of 0 indicates absence of panic attacks (PA), an index of 12 the most severe form of syndromal panic

subset analysis) as proposed by Macgregor et al. (2006). For this purpose, we ordered patients according to the severity of syndromal panic attacks using the subscale "severity of panic attacks" of the panic and agoraphobia scale (PAS). We then created six subsets of patients (Table 3). Subset I included all study patients with valid
PAS entries (scoring from 0 to 12 on this psychopathology scale). For subsets II-VI, patients with the least severity of panic attacks were removed sequentially according to the cut-off scores detailed in Table 3. In subset VI, only cases with most severe syndromal panic attacks were included. We then performed case-control associations sequentially for each subgroup. We detected the most significant associations of SLC6A1 polymorphisms when we compared patients in subset $\mathrm{V}(\mathrm{PAS} \geq 8$ ) with controls (Fig. 2a). The highest nominal associations were found for rs2930152 ( $P$ $=9.71 \mathrm{e}-5)$ and for $\operatorname{rs} 2697153(P=0.000119)$ which both withstood permutation-based correction for multiple testing for all tested SNPs $(n=20)$ and phenotypes $(n=6)$ (rs2930152: $P=0.0083$ and rs2697153: $P=0.0101$ ). For these two SNPs, we observed a constant increase of the disease odds ratio (OR) with the increase in panic severity, as illustrated in Fig. 2b. While highest associations were found with subset $\mathrm{V}$, we observed an even higher disease OR at both loci for subset VI (i.e., most severely affected
Fig. 2 Sequential analysis of patient subsets versus controls. Illustration of nominal $P$ values for all genotyped SNPs in the genomic order as presented for the analysis of patient subset $\mathrm{V}$ versus controls (a). Constant increases of the odds ratio (OR) along clusters for rs2930152 and rs2697153; dotted lines assign upper and lower confidence intervals of $95 \%$ (b). Distribution of alleles (\%) of rs2930152 and rs2697153 within anxiety disorder patients of subset $\mathrm{V}(n=60$; black bars $)$ and controls $(n=267$; white bars); numbers indicate the total number of alleles in each group (c)
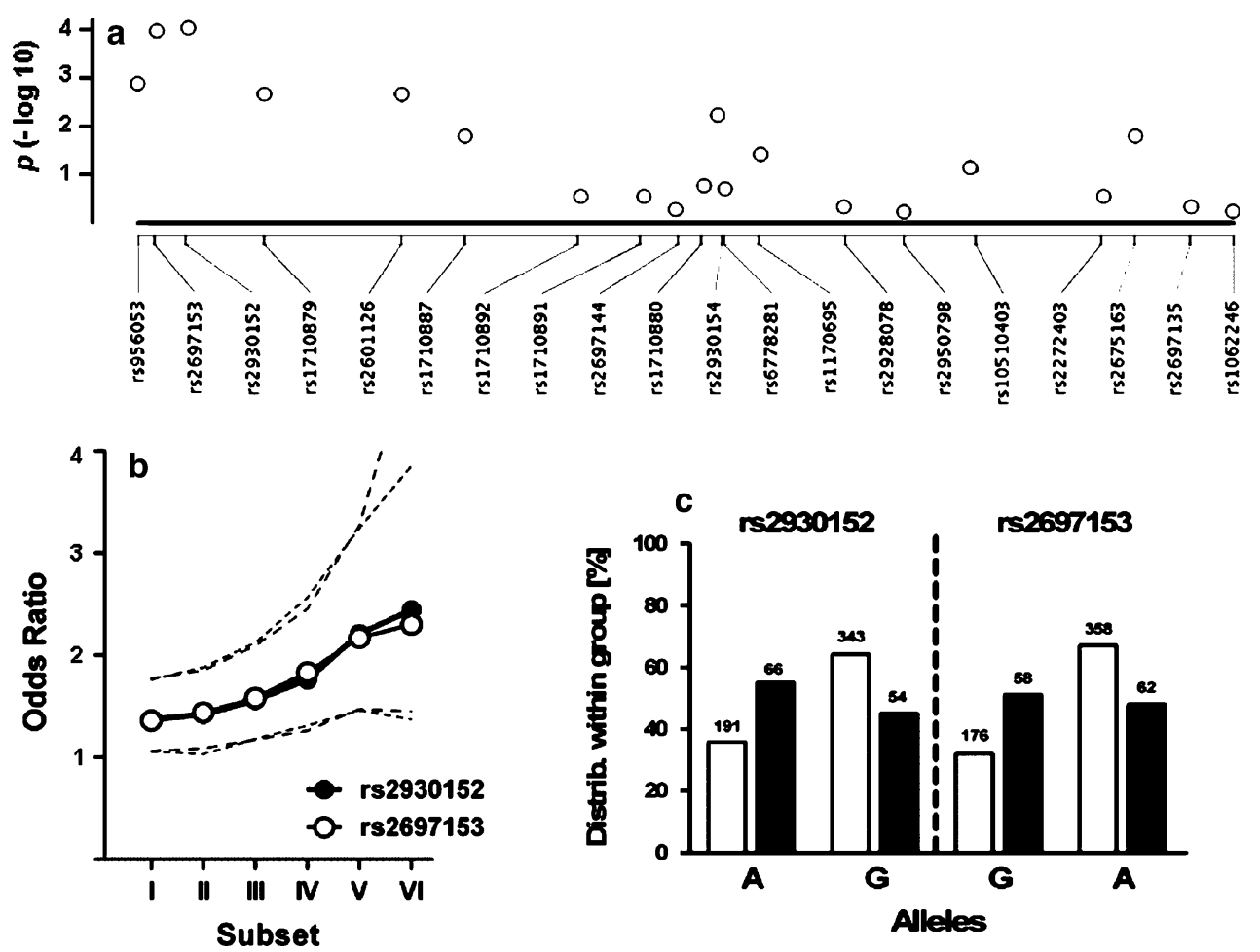
subjects). However, the small sample size for this subgroup reduces the power to detect significant case-control associations [cf. increase of $95 \%$ confidence interval (CI); Fig. 2b).

The strong case-control association of rs2930152 with subset $\mathrm{V}$ of our patient sample is reflected by an overrepresentation of the G-allele in healthy controls with an OR of 2.20 (CI: 1.47-3.27), thus exerting a protective effect. Likewise, the A-allele is significantly more prevalent in controls at the rs2697153 locus (Fig. 2c). The protective effect of this allele has an OR of 2.17 (CI: 1.463.24). When comparing the distribution of alleles within cases and controls across patient subsets, we observed the under-representation of the G-allele at rs2930152 and of the A-allele at rs2697153 locus in every patient subset compared to controls with decreasing prevalence along increases in anxiety severity [rs2930152 G-allele frequencies: $64.2 \%$ (controls), $56.7 \%$ (subset I), $55.8 \%$ (II), $53.5 \%$ (III), $50.5 \%$ (IV), $45.0 \%$ (V), $42.4 \%$ (VI); rs2697153 Aallele frequencies: $67.0 \%$ (controls), $59.9 \%$ (subset I), $58.6 \%$ (II), $56.3 \%$ (III), $52.6 \%$ (IV), $48.3 \%$ (V), $47.0 \%$ (VI)].

We further calculated a Fisher product combined genewide significance applying 100.000 permutations for cases of subset $\mathrm{V}$ versus controls and detected a $P$ value of 0.00013 , withstanding even Bonferroni correction for all performed tests $(P=0.0156)$. A list of all data for the genetic associations with all genotyped SNPs across the patients' subsets including the results for Fisher product combined testing is available online (Electronic supplementary material, Tables 1 and 2).

\section{Discussion}

In our candidate gene association study we provide first evidence of a possible association of specific genetic variants within the SLC6A1 locus encoding GAT-1 with anxiety disorders with syndromal panic attacks. Furthermore, two SNPs located in the $5^{\prime}$ region of this gene showed an increasing strength of association when patients were stratified according to the severity of panic symptoms, suggesting that our association results may be more specific for the development and severity of panic attacks than anxiety disorders per se.

Panic attacks are circumscribed episodes of severe state anxiety lasting minutes to hours with escalating symptoms. While panic attacks are the hallmark of panic disorder, they also occur regularly in association with other anxiety disorders such as, e.g., social phobia or specific phobia.

When we ordered patients according to the increase in panic symptom severity, the two SNPs rs2930152 and rs2697153, which are in strong LD $\left(r^{2}=1\right)$, showed a substantial increase in the strength of case-control associations. The disease OR of each SNP at different subsets displayed a constant increase reaching a value of almost 2.5 when limiting the case groups to patients with severe panic attacks (PAS $>8$ ). This suggests that the reported finding represents an association with a specific symptom of anxiety disorders (i.e., panic attacks) rather than with a DSM-IV based diagnosis and displays a higher OR than observed in classical case-control association studies with complex psychiatric disorders (Lohmueller et al. 2003).

With respect to a possible functional relevance of these SNPs we would like to note that both polymorphisms are located in the $5^{\prime}$ flanking region of SLC6A1 with some distance $(10 \mathrm{~kb})$ from exon 1 of our candidate gene and putative promoter regions as predicted by the ElDorado software (data not shown; www.genomatix.de). At this point, however, we cannot rule out that these SNPs tag another more causally related genetic variant. The LD block that contains these two SNPs stretches from exon 1 to at least $11 \mathrm{~kb}$ upstream of the $5^{\prime}$ end of the gene (data according to LD mapping in our study sample), therefore including the potential $5^{\prime}$ promoter region (see Fig. 1). This block, however, ends before the $5^{\prime}$ neighbouring gene SLC6A11 as shown in the International HapMap Project data (www.hapmap.org) suggesting that the observed association with pathological anxiety does indeed represent an association with the SLC6A1 locus.

While awaiting replication in independent samples, our data may further highlight the major role of the GABAergic system in anxiety disorders and, especially, in the panic phenotype.

Current clinical and preclinical studies support our evidence that genetic variants in the gene encoding GAT-1 could play an important role in the pathogenesis of pathological anxiety states. Recent human studies suggest that tiagabine, a selective blocker of GAT-1, possesses anxiolytic properties in a variety of anxiety disorders (for review see Schwartz and Nihalani 2006). Another line of evidence for an involvement of GABA transport, the main regulator of extracellular GABA, comes from magnetic resonance spectroscopy studies in anxiety disorder patients which revealed a significant reduction of GABA concentrations in several brain areas highly relevant in emotion and behaviour (Goddard et al. 2001; Ham et al. 2007; Pollack et al. 2008). It has been suggested that these reductions resemble a trait-like abnormality and might be influenced by familial factors (Goddard et al. 2004a, 2004b). Furthermore, using segregation analyses in families with affective disorders, Petty et al. (1999) report that plasma membrane GABA levels are genetically controlled, probably through autosomal recessive transmission. Using preclinical models of anxiety, the pharmacological inhibition of GAT-1 in rats has been shown to exert anxiolytic-like actions (Schmitt 
Table 4 Summary of human genetic studies linking the GABA system to anxiety disorders and related personality traits

\begin{tabular}{|c|c|c|c|c|c|}
\hline Genes & Polymorphisms & Phenotypes & Analyses & Findings & References \\
\hline $\begin{array}{l}\text { Glutamate } \\
\text { decarboxylase } 1 \\
\text { (GAD1) }\end{array}$ & 2q31.1; 5 SNPS & $\begin{array}{l}\text { GAD, PD, } \\
\text { Agoraphobia, } \\
\text { social phobia }\end{array}$ & $\begin{array}{l}\text { Case-control (589 cases, } \\
539 \text { patients) }\end{array}$ & $P=0.032$ & Hettema et al. (2006) \\
\hline $\begin{array}{l}\text { Glutamate } \\
\text { decarboxylase } 2 \\
\text { (GAD2) }\end{array}$ & 10p11; dinucleotide RP & $\begin{array}{l}\text { Anxiety trait } \\
\text { (behavioural } \\
\text { inhibition) }\end{array}$ & Linkage (66 pedigrees) & $P=0.05$ & Smoller et al. (2001) \\
\hline GABRA6 & $5 q 34 ; 1 \mathrm{SNP}$ & $\begin{array}{l}\text { Anxiety trait } \\
\quad \text { (neuroticism) }\end{array}$ & $\begin{array}{l}\text { Dimensional (419 } \\
\text { subjects) }\end{array}$ & $P=0.003$ & Sen et al. (2004) \\
\hline GABRA6 & $5 q 34 ; 1 \mathrm{SNP}$ & PD & $\begin{array}{l}\text { Case-control ( } 87 \\
\quad \text { patients, } 114 \text { controls) }\end{array}$ & $P=\mathrm{NS}$ & Kobayashi et al. (2007) \\
\hline $\begin{array}{c}\text { GABRA1-5, } \\
\text { GABRB1, } \\
\text { GABRB3 }\end{array}$ & $\begin{array}{l}\text { 4p14-q12, 5q32-35, } \\
\text { 15q11-13, Xq28; } \\
\text { (CT)n RP }\end{array}$ & PD w/o Agoraphobia & Linkage (26 pedigrees) & $P=\mathrm{NS}$ & Crowe et al. (1997) \\
\hline \multicolumn{6}{|l|}{ GABRG2 } \\
\hline GABRB1 & 4p13; tetranucleotide RP & PD & Linkage (5 pedigrees) & $P=\mathrm{NS}$ & Schmidt et al. 1993 \\
\hline GABRB3 & 15q11-13; dinucleotide RP & PTSD & Dimensional (86 subjets) & $P=0.0002$ & Feusner et al. (2001) \\
\hline GABBR1 & 4p13; 3 SNPs & PD & $\begin{array}{l}\text { Case-control ( } 87 \\
\text { patients, } 89 \text { controls) }\end{array}$ & $P=\mathrm{NS}$ & Sand et al. (2000) \\
\hline $\begin{array}{l}\text { Diazepam binding } \\
\text { inhibitor (DBI) }\end{array}$ & 2p14.2; $1 \mathrm{SNP}$ & $\begin{array}{l}\text { Anxiety disorders with } \\
\text { PA }\end{array}$ & $\begin{array}{l}\text { Case-control (176 } \\
\text { patients, } 301 \text { controls) }\end{array}$ & $P=0.032$ & Thoeringer et al. (2007) \\
\hline
\end{tabular}

$G A B R A \gamma$-aminobutyric acid receptor type A, alpha subunit; $G A B R B \gamma$-aminobutyric acid receptor type A, beta subunit; $G A B R G \gamma$-aminobutyric acid receptor type A, gamma subunit; GABBR aminobutyric acid receptor type B (for further details on gene names and symbols see HUGO Gene Nomenclature Committee, www.genenames.org), GAD generalized anxiety disorder, $N S$ not significant, $R P$ repeat polymorphisms, $P D$ panic disorder, $P A$ panic attacks, $P T S D$ posttraumatic stress disorder, SNP single nucleotide polymorphism

and Hiemke 1999; Schmitt et al. 2002). Likewise, mice deficient of the GAT-1 gene display lower levels of anxiety-like behaviours in comparison to wild-type animals (Liu et al. 2007). Using another genetic knock-out (KO) approach of GAT-1, Chiu et al. (2005) observed a large gene-dose effect on the behavioural performance of KO mice. Importantly, this finding implicates that even subtle changes in the expression or function due to genetic modifications of GAT-1 within the CNS may have a strong impact on emotional behaviours such as fear and anxiety.

The polygenic model for the genetic susceptibility for complex diseases (Falconer 1967) suggests that several genes, all of a modest impact, contribute to the genetic susceptibility to develop or maintain complex pathologies such as anxiety disorders. So far, a multitude of positive findings linking genetic polymorphisms to anxiety disorder liability has been reported (for review, Finn et al. 2003; Gratacos et al. 2007; Hovatta and Barlow 2008), although replication in independent cohorts often failed due to phenotypic or genetic heterogeneity and methodological issues (Kendler 2005; Munafo 2006).

As summarized in Table 4, several human genetic linkage and association studies have investigated the genetic load of GABA system pathways on the psychobiology of anxiety. Positive signals for an association with anxiety disorders and anxiety-related personality traits have been observed for genes encoding glutamic acid decarboxylase, the $\alpha 6$ and $\beta 3$ subunits of the $\mathrm{GABA}_{\mathrm{A}}$ receptor, type $1 \mathrm{GABA}_{\mathrm{B}}$ receptor and the diazepam binding inhibitor. These published observations, together with our findings, may implicate a multiple system hit-theory in the genetic underpinning of anxiety disorder as it was recently described for the lithium-sensitive phoshatidylinositol pathway in the genetic susceptibility for bipolar disorder (Baum et al. 2008). Thus, no single genetic polymorphism or a small set of SNPs within a component of this neuroinhibitory pathway is sufficient to trigger the disease. However, many loci at different genes of the GABA system, each of a small effect size, may contribute to an individual's disease risk. If the person's total burden of risk loci reaches some threshold, pathological anxiety could develop under the influence of adverse exogenic factors.

\section{Conclusion}

In essence, our results indicate that genetic variance in SLC6A1 may be associated with the aetiopathogenesis of anxiety disorders and, importantly, may modulate the severity of panic attacks in these patients. Although this study lacks independent confirmation and further data about the neurobiological relevance of our findings, it supports the involvement of a dysregulation in GABAergic 
circuits in pathological anxiety and highlights GAT-1 as a promising target for the treatment of anxiety disorders and specifically for panic symptoms. First positive clinical studies with GAT-1 inhibitors substantiate this idea.

Acknowledgments The authors would like to thank Stefan Kloiber, Sonja Horstmann, Hubertus Himmerich, Martin Kohli, Daria Salyakina, Angela Heck, Andrea Ellgas, Hildegard Pfister and Roselind Lieb for their valuable help in performing the studies, Maria Asmus, Sabine Damast, Maik Koedel, Angelika Sangl, Susann Sauer and Alina Tontsch for expert technical assistance. This work has been funded by the Bavarian Ministry of Commerce and by the Federal Ministry of Education and Research (BMBF) within the framework of the National Genome Research Network (NGFN), Förderkennzeichen 01GS0481. The authors are responsible for the contents of this publication.

Open Access This article is distributed under the terms of the Creative Commons Attribution Noncommercial License which permits any noncommercial use, distribution, and reproduction in any medium, provided the original author(s) and source are credited.

\section{References}

Alonso J, Angermeyer MC, Bernert S et al (2004) Prevalence of mental disorders in Europe: results from the European Study of the Epidemiology of Mental Disorders (ESEMeD) project. Acta Psychiatr Scand 109(Suppl 429):21-27

Bandelow B (1995) Assessing the efficacy of treatments for panic disorder and agoraphobia, II: the Panic and Agoraphobia Scale. Int Clin Psychopharmacol 10:73-81

Baum AE, Akula N, Cabanero M et al (2008) A genome-wide association study implicates diacylglycerol kinase eta (DGKH) and several other genes in the etiology of bipolar disorder. Mol Psychiatry 13:197-207

Binder EB, Salyakina D, Lichtner P et al (2004) Polymorphisms in FKBP5 are associated with increased recurrence of depressive episodes and rapid response to antidepressant treatment. Nat Genet 36:1319-1325

Carpenter LL, Schecter JM, Tyrka AR et al (2006) Open-label tiagabine monotherapy for major depressive disorder with anxiety. J Clin Psychiatry 67:66-71

Chiu CS, Brickley S, Jensen K et al (2005) GABA transporter deficiency causes tremor, ataxia, nervousness, and increased GABA-induced tonic conductance in cerebellum. J Neurosci 25:3234-3245

Connor KM, Davidson JRT, Weisler RH et al (2006) Tiagabine for posttraumatic stress disorder: effect of open-label and double-blind discontinuation treatment. Psychopharmacology 184:21-25

Crowe RR, Wang Z, Noyes R et al (1997) Candidate gene study of eight $\mathrm{GABA}_{\mathrm{A}}$ receptor subunits in panic disorder. Am J Psychiatry $154: 1096-1100$

Dalby NO (2003) Inhibition of gamma-aminobutyric acid uptake: anatomy, physiology and effects against epileptic seizures. Eur J Pharmacol 479:127-137

Devlin B, Roeder K (1999) Genomic control for association studies. Biometrics 55:997-1004

Falconer DS (1967) The inheritance of liability to diseases with variable age of onset, with particular reference to diabetes mellitus. Ann Hum Genet 31:1-20

Feusner J, Ritchie T, Lawford B et al (2001) $\mathrm{GABA}_{\mathrm{A}}$ receptor $\beta 3$ subunit gene and psychiatric morbidity in a post-traumatic stress disorder population. Psychiatry Res 104:109-117
Finn DA, Rutledge-Gorman MT, Crabbe JC (2003) Genetic animal models of anxiety. Neurogenetics 4:109-135

Fisher RA (1932) Statistical methods for research workers. Oliver and Boyd, London

Gabriel SB, Schaffner SF, Ngyuen H et al (2002) The structure of haplotype blocks in the human genome. Science 296:2225-2229

Goddard AW, Mason GF, Almai A et al (2001) Reductions in occipital cortex GABA levels in panic disorder detected with $1 \mathrm{H}$-magnetic resonance spectroscopy. Arch Gen Psychiatry 58:556-561

Goddard AW, Mason GF, Rothman DL et al (2004a) Family psychopathology and magnitude of reductions in occipital cortex GABA levels in panic disorder. Neuropsychopharmacology 29:639-640

Goddard AW, Mason GF, Appel MS et al (2004b) Impaired GABA neuronal response to acute benzodiazepine administration in panic disorder. Am J Psychiatry 161:2186-2193

Gratacos M, Sahun I, Gallego X et al (2007) Candidate genes for panic disorder: insights form human and mouse genetic studies. Genes Brain Behav 6(Suppl 1):2-23

Ham BJ, Sung Y, Kim N et al (2007) Decreased GABA levels in anterior cingulated and basal ganglia in medicated subjects with panic disorder: a proton magnetic resonance spectroscopy $(1 \mathrm{H}-$ MRS) study. Prog Neuropsychopharmacol Biol Psychiatry 31:403-411

Hamilton M (1959) The assessment of anxiety-states by rating. $\mathrm{Br}$ J Med Psychol 32:50-55

Hamilton M (1960) A rating scale for depression. J Neurol Neurosurg Psychiatry 23:56-62

Hettema JM, Prescott CA, Myers JM et al (2005) The structure of genetic and environmental risk factors for anxiety disorders in men and women. Arch Gen Psychiatry 62:182-189

Hettema JM, An SS, Neale MC et al (2006) Association between glutamic acid decarboxylase genes and anxiety disorders, major depression, and neuroticism. Mol Psychiatry 11:752-762

Horwath E, Wolk SI, Goldstein RB et al (1995) Is the comorbidity between social phobia and panic disorder due to familial cotransmission or other factors? Arch Gen Psychiatry 52:574-582

Hovatta I, Barlow C (2008) Molecular genetics of anxiety in mice and men. Ann Med 40:92-109

Kalueff A, Nutt DJ (1996-1997) Role of GABA in memory and anxiety. Depress Anxiety 4:100-110

Kalueff AV, Nutt DJ (2007) Role of GABA in anxiety and depression. Depress Anxiety 24:495-517

Kendler KS (2005) Psychiatric genetics: a methodologic critique. Am J Psychiarty 162:3-11

Kessler RC, Berglund P, Demler O et al (2005a) Lifetime prevalence and age-of-onset distributions of DSM-IV disorders in the National Comorbidity Survey Replication. Arch Gen Psychiatry 62:593-602

Kessler RC, Chiu WT, Demler O et al (2005b) Prevalence, severity, and comorbidity of 12-month DSM-IV disorders in the National Comorbidity Survey Replication. Arch Gen Psychiatry 62:617627

Kobayashi Y, Akiyoshi J, Kanehisa M et al (2007) Lack of polymorphism in genes encoding mGluR7, mGluR8, GABA(A) receptor alfa-6 subunit and nociceptin/orphanin FQ receptor and panic disorder. Psychiatr Genet 17:9

LaRoche SM, Helmers SL (2004) The new antiepileptic drugs. JAMA 291:605-614

Liu GX, Cai GQ, Cai YQ et al (2007) Reduced anxiety and depression-like behaviours in mice lacking GABA transporter subtype 1 . Neuropsychopharmacology 32:1531-1539

Lohmueller KE, Pearce CL, Pike M et al (2003) Meta-analysis of genetic association studies support a contribution of common variants to susceptibility to common disease. Nat Genet 33:177182 
Low NCP, Cui L, Merikangas KR (2008) Specificity of familial transmission of anxiety and comorbid disorders. J Psych Res 42(7):596-604

Macgregor S, Craddock N, Holmans P (2006) Use of phenotypic covariates in association analysis by sequential addition of cases. Eur J Hum Genet 14:529-534

Mayer EA, Craske M, Naliboff BD (2001) Depression, anxiety, and the gastrointestinal system. J Clin Psychiatry 62(Suppl 8):28-36

Merikangas KR, Zhang H, Avenevoli S et al (2003) Longitudinal trajectories of depression and anxiety in a prospective community study. Arch Gen Psychiatry 60:993-1000

Munafo MR (2006) Candidate gene studies in the 21st century: metaanalysis, mediation, moderation. Genes Brain Behav 5(Suppl 1):3-8

Nemeroff CB (2003) The role of GABA in the pathophysiology and treatment of anxiety disorders. Psychopharmacol Bull 37:133-146

Nocon A, Wittchen HU, Beesdo K et al (2007) Differential familial liability of panic disorder and agoraphobia. Depress Anxiety $0: 1-13$

Petty F, Fulton M, Kramer GL et al (1999) Evidence for the segregation of a major gene for human plasma GABA levels. Mol Psychiatry 4:587-589

Pollack MH, Roy-Byrne PP, van Ameringen M et al (2005) The selective GABA reuptake inhibitor tiagabine for the treatment of generalized anxiety disorder: results of a placebo-controlled study. J Clin Psychiatry 66:1401-1408

Pollack MH, Jensen JE, Simon NM et al (2008) High-field MRS study of GABA, glutamate and glutamine in social anxiety disorder: Response to treatment with levetiracetam. Prog Neuropsychopharmacol Biol Psychiatry 32:739-743

Rogawski MA, Loescher W (2004) The neurobiology of antiepileptic drugs for the treatment of nonepileptic conditions. Nat Med 10:685-692

Rosenthal M (2003) Tiagabine for the treatment of generalized anxiety disorder: a randomized, open-label, clinical trial with paroxetine as a positive control. J Clin Psychiatry 64:1245-1249

Sand PG, Godau C, Riederer P et al (2000) Exonic variants of the GABA(B) receptor gene and panic disorder. Psychiatr Genet 10:191-194

Sarup A, Larsson OM, Schousboe A (2003) GABA transporters and GABA-transaminase as drug targets. Curr Drug Targets CNS Neurol Disord 2:269-277
Schmidt SM, Zoëga T, Crowe RR (1993) Excluding linkage between panic disorder and the gamma-aminobutyric acid beta 1 receptor locus in five Icelandic pedigrees. Acta Psychiatr Scand 88:225228

Schmitt U, Hiemke C (1999) Effects of GABA-transporter (GAT) inhibitors on rat behaviour in open-field and elevated plus-maze. Behav Pharmacol 10:131-137

Schmitt U, Lüddens H, Hiemke C (2002) Anxiolytic-like effects of acute and chronic GABA transporter inhibition in rats. J Neural Transm 109:871-880

Schwartz TL, Nihalani N (2006) Tiagabine in anxiety disorders. Expert Opin Pharmacother 7:1977-1987

Sen S, Villafuerte S, Nesse R et al (2004) Serotonin transporter and $\mathrm{GABA}(\mathrm{A})$ alpha 6 receptor variants are associated with neuroticism. Biol Psychiatry 55:244-249

Sheehan DV, Sheehan KH, Raj BA et al (2007) An open-label study of tiagabine in panic disorder. Psychopharmacol Bull 40:32-40

Smoller JW, Rosenbaum JF, Biedermann J et al (2001) Genetic association analysis of behavioral inhibition using candidate loci from mouse models. Am J Med Genet b Neuropsychiatr Genet 105:226-235

Thoeringer CK, Binder EB, Salyakina D et al (2007) Association with a Met88Val diazepam binding inhibitor (DBI) gene polymorphism and anxiety disorders with panic attacks. J Psychiatr Res 41:579-584

Westfall PH, Young SS (1993) Resampling-based multiple testing: examples and methods for $p$-value adjustment. Wiley, New York

Wittchen HU (1994) Reliability and validity studies of the WHOComposite International Diagnostic Interview (CIDI): a critical review. J Psychiatr Res 28:57-84

Wittchen HU, Zaudig M, Fydrich T (1997) Strukturiertes klinisches Interview für DSM-IV. Achse I and II. Hogrefe, Göttingen

Wittchen HU, Pfister H (1997) DIA-X-Interviews: Manual für Screening-Verfahren und Interview. Swets \& Zeitlinger, Frankfurt

Zwanzger P, Rupprecht R (2005) Selective GABAergic treatment for panic? Investigations in experimental panic induction and panic disorder. J Psychiatry Neurosci 30:167-175

Zwanzger P, Baghai T, Schüle C et al (2001) Tiagabine improves panic and agoraphobia in panic disorder patients. J Clin Psychiatry 62:656-657 